\title{
Educação, Sociedade e Formação em Sistemas de Informação
}

\section{Title: Education, Society and Higher Education in Information Systems}

\author{
Tiago de Jesus Braga ${ }^{1,2}$, Leonardo Cruz da Costa $^{1}$, Isabel Cafezeiro ${ }^{1}$ \\ ${ }^{1}$ Instituto de Computação - Universidade Federal Fluminense (UFF) \\ Niterói - RJ - Brasil \\ ${ }^{2}$ Mestrado Profissional em Matemática (UNIRIO) \\ Rio de Janeiro - Brasil \\ \{tiago, leo, isabel\}@ic.uff.br
}

\begin{abstract}
The effectiveness of research and development in Information Systems depends and influences the social processes that unfold in their environment. We argue here that the field of Information Systems needs to build its identity with (not for) society. This means a process of coconstruction that requires reflection on the social context at all levels, starting with the curriculum design and functional organization of the courses. We present the process of construction of the undergraduate course on Information Systems at the Federal Fluminense University highlighting the commitment to social responsibility, the contributions resulting from the choice of night teaching and the dialogical interaction with the labour market.
\end{abstract}

Keywords. Education; Society; Higher Education; Night Teaching.

Resumo. A efetivação das pesquisas e desenvolvimentos em Sistemas de Informação (SI) depende e influencia os processos sociais que se desenrolam em seu ambiente de implantação e entornos. Argumentamos que o campo de SI precisa construir sua identidade com (e não para) a sociedade. Isto significa um processo de co-construção que requer refletir sobre a conjuntura social em todos os níveis, a começar pela concepção dos currículos e organização funcional dos cursos. Apresentamos o processo de construção do curso de SI da Universidade Federal Fluminense ressaltando o compromisso com a conjuntura social, contribuições alcançadas pela escolha pelo período noturno e dialógica com o mercado de trabalho.

Palavras-Chave. Educação; Sociedade; Educação Superior, Ensino Noturno.

\section{Introdução}

Partimos da constatação de que, desde o início da formação do campo de Sistemas de Informação, já se sabia do inevitável imbricamento entre as questões sociais e o sucesso na implantação e operação de sistemas de formação [Wiener 1948/1985,1950/1989]. 
Esta compreensão tem registros na literatura científica no Brasil [Cukierman, Teixeira $\&$ Prikladnicki 2007] e no exterior ${ }^{1}$ [Woolgar 1991, Law e Bijker, 2000]. No entanto, há diferentes abordagens em face à percepção deste imbricamento e à efetivação das práticas sob a luz de sua compreensão. Algumas abordagens chamadas sócio-técnicas operam sobre uma cisão entre um domínio social e outro técnico. Consideram que decorre daí uma partição entre duas culturas, uma das ciências exatas e das técnicas e outra das artes e humanidades. A partir daí, elaboram soluções sistêmicas ou estruturadas sob o entendimento que um sistema é composto por partes autônomas que devem interagir e cooperar para que o todo (sistema) funcione satisfatoriamente, buscam mecanismos de diálogo e interação entre os domínios das técnicas e das humanidades. Outras abordagens adotam uma perspectiva sociotécnica, ou seja, apontam a impossibilidade de haver um domínio que seja essencialmente técnico ou essencialmente social. Reconhecem a cisão entre as duas culturas como uma construção decorrente de compromissos e interesses, e assumem a postura epistemológica de atuar no hibridismo (espaço de indistinção entre o que seria dito técnico e o que seria dito social). Buscam mostrar evidências de que o conhecimento (mesmo os saberes técnicos) é uma construção coletiva, ou seja, depende de pessoas, preferências, políticas, matemáticas, sociedade, técnicas, cultura, época, local, etc, e portanto, a produção do conhecimento se dá sobre um espaço híbrido.

Passamos a exemplos de autores que reconhecem e trabalham sobre esse espaço híbrido (não necessariamente tratando da construção de currículos). Daston e Galison [2010], publicado originalmente em 2007, aborda o conceito de objetividade científica, argumentando que, tanto quanto a subjetividade, este é um conceito historicamente construído. Os autores mostram como ocorreu na era moderna a associação do termo "objetividade" com as noções de clareza, correção, exatidão e abstração, bem como a ligação entre "subjetividade" com questões da pessoa, das preferências, das artes. Para isso, o texto enreda indistintamente elementos que seriam pertinentes aos domínios "técnico" e "social" de modo que um leitor aderente à usual separação entre as duas culturas encontra dificuldades em se situar nas perspectivas da técnica ou da sociedade. Um outro autor, Shapin [2010], já deixa claro em seu longo título "Never Pure. Historical Studies of Sciences as if It Was Produced by People with Bodies, Situated in Time, Space, Culture, and Society, and Struggling for Credibility and Authority" que o conhecimento é indistintamente construído por um jogo de forças que envolve credibilidade e autoriadade. Já "Trust in Numbers: The Pursuit of Objectivity in Science and Public Life", de Theodore Porter [1996], fala de uma "tecnologia da confiança" sobre números, deixando claro a relação de poder e autoridade que as abordagens

\footnotetext{
${ }^{1}$ As primeiras propostas curriculares surgidas a partir da década de 1970 nos Estados Unidos se apresentavam sob enfoque organizacional, referindo-se principalmente a empresas, de acordo com o uso que se fazia de sistemas de informação naquele momento histórico, naquele país [Ashenhurst, 1973,1972]. Décadas mais tarde, estas propostas evoluíram para o enfoque de negócios (business) [Davis et al, 1997], e já na década de 2002 mostravam um claro compromisso com a abordagem empresarial: "IS professionals must have a broad business and real world perspective (...) must design and implement information technology solutions that enhance organizational performance." [Davis et al,2002]. Este percurso acompanhou as necessidades históricas de países cujo panorama tecnológico diferia completamente da situação brasileira. Por este motivo, a compreensão do campo e a concepção de currículos com base nestes documentos não atendem a especificidades brasileiras, desconsiderando o percurso histórico de construção da computação no Brasil. Neste artigo priorizamos as abordagens nacionais e internacionais que propõem a compreensão do campo em suas relações com a sociedade (não somente com o mundo dos negócios).
} 
matematizadas exercem sobre nós. Para acrescentar um estudo aplicado brasileiro, Nascimento [2016] também trabalha sobre este espaço de mistura entre números e sociedade mostrando que os usuais indicadores de desempenho são construídos de modo a favorecer interesses, embora sejam apresentados como se fossem aptos a operar em quaisquer circunstâncias. Ele aborda empreendimentos voltados a grupos de alta vulnerabilidade social e mostra o resultado desastroso de avaliar esses empreendimentos através dos usuais indicadores de desempenho já aceitos e estabilizados em nossa sociedade. Esses trabalhos demonstram que a usual separação entre as duas culturas não dá luz à complexidade de relações que se estabelecem no espaço de hibridismo entre o que se diria "técnico" e o que se diria "social". Ainda mais, os estudos estratificados, estruturados, sistematizados, separados em partes reforçam as relações de domínios de uma parte sobre a outra, de uma cultura sobre a outra.

No texto que se segue, vamos tratar da formação profissional em Sistemas de Informação, sob o ponto de vista sociotécnico. Ou seja, situamos Sistemas de Informação como um campo híbrido, conformado no encontro de diversas disciplinas como Ciência da Computação, Administração, Psicologia, Sociologia, Direito, História, Ciências da Informação, dentre outras. Diferente de [Cafezeiro, Costa, Kubrusly, 2016, Cukierman, Teixeira \& Prikladnicki, 2007] o foco aqui não é ressaltar a abordagem sociotécnica na formação curricular, ou seja, entre e inter disciplinas, mas argumentar que a preocupação com a sociedade deve ultrapassar conteúdos ensinados e se manifestar nas práticas de concepção, instalação e operação do próprio curso. Tomando já como certa a compreensão de que Sistemas de Informação necessita ser um campo socialmente consciente [Araújo, Maciel, Boscarioli, 2017, p.55-57], argumentamos que compromisso social precisa ser exercido e praticado pela comunidade acadêmica para que possa ser ensinado como prática profissional dos egressos. Mas esse compromisso não se efetiva em uma prática filantrópica ou beneficiente, mas na constatação de que o curso de Sistemas de Informação (incluindo-se aí: currículos, docentes, discentes, técnicos administrativos, funcionários terceirizados, e toda a comunidade diretaindiretamente presente) faz parte da sociedade, mistura-se a ela de maneira indissociável, e portanto precisa compreender-se como parte dela para que possa fornecer uma formação adequada. Nossos argumentos giram em torno de um estudo de casos: o percurso de construção do curso de Bacharelado em Sistemas de Informação da Universidade Federal Fluminense, e o texto é organizado da seguinte forma:

Na seção 2 conceituamos a área de Sistemas de Informação e traduzimos o termo "Responsabilidade Social" para abranger o sentido que nos interessa nesse texto. Seguindo a perspectiva de John Law [1977] de que toda tradução é também traição, desvirtuamos o termo de sua concepção amplamente adotada na década de 1990, quando as empresas buscavam justificativas sociais compensatórias para seus empreendimentos lucrativos. O conceito "Responsabilidade Social" [ABNT,2004] foi então cunhado como uma iniciativa das empresas em favor da sociedade. Pretendemos aqui desestabilizar duas questões referentes a este entendimento do termo: primeiro a compreensão de "sociedade" como um corpo coeso, uniforme, inequívoco, estabilizado. Isto demonstra a desconsideração do caráter local, em sua dinâmica e fluxo. Segundo a referência à sociedade como se as empresas fossem organismos desvinculados dela, e portanto aptos a adotar atitudes beneficentes a ela. Sob uma compreensão de coconstrução, e portanto, rejeitando essas duas questões, re-situamos a importância da responsabilidade social na formação em Sistemas de Informação. 
Na seção 3, acompanhamos o percurso de implantação do curso de Sistemas de Informação da Universidade Federal Fluminense a partir de duas abordagens que foram pensadas no âmbito da Teoria Ator-Rede. A chamada "Cartografia das Controvérsias" [Latour, 2012] busca auxiliar a explorar e visualizar polêmicas e controvérsias, em sua maioria relacionadas às questões técnico-científicas, e de preferência, tratando-se de controvérsias recentes, ainda não estabilizadas. A Cartografia das Controvérsias traz para a cena as relações de forças que se fazem presentes numa controvérsia, deixando visíveis as articulações e interesses que vão se conformando ao longo do processo. Nessa trajetória, entram em cena atores que não necessariamente estariam presentes nas abordagens tradicionais, uma vez que estas são fortemente calçadas sobre bases fixadas e portanto autoritárias: livros, artigos, dicionários, etc. Junto com a Cartografia das Controvérsias também nos orientamos pela abordagem "PesquisarCom" [Bernardes, Tavares \& Moraes, 2004], que percebe que pesquisar implica necessariamente em uma articulação com o que se produz na pesquisa, e a partir daí procura deslocar a postura de comprovação da realidade para percepções de criação da realidade. Este deslocamento contribui para favorecer uma postura mais horizontal com relação aos diversos atores da controvérsia em questão, de modo a desestabilizar papéis firmemente estabelecidos (por exemplo, de que o aluno escuta/aprende e que o professor fala/ensina) e permitir a reelaboração destes papéis no fluxo das relações de cooperação que se desenvolvem coletivamente. As duas abordagens aqui citadas se ambientam na Teoria Ator-Rede [Bijker and Law, 1992, Bijker, 1995] e estimulam uma atitude situada com relação ao assunto a ser tratado, ou seja, demandam descrições onde nomes, datas e locais precisam ser explicitamente mencionados, esquivando-se de relatos globalizantes e atemporais.

Na seção 4, apresentamos estatísticas atuais sobre o funcionamento do curso de modo a validar as estratégias sociais pensadas na época da concepção do curso. Dentre essas estratégias destaca-se a escolha do horário noturno que ainda hoje representa um incômodo à grande parte dos docentes do Instituto.

Finalmente, na seção 5 consideramos as contribuições que este estudo embasado pela Cartografia das Controvérsias e PesquisarCom podem oferecer à formação da identidade do campo de Sistemas de Informação. Concluímos o artigo com base na abordagem de Desenvolvimento Local, de Ladislau Dowbor, ressaltando algumas questões que sobressaíram na consolidação de um curso socialmente comprometido. Foram elas a interdisciplinaridade, o diálogo com o mercado de trabalho, o horário noturno, a busca por mecanismos didáticos participativos e a observação à realidade local.

\section{Sistemas de Informação e Sociedade}

Este trabalho consolida-se no sentido de apresentar o percurso de construção do curso de Bacharelado em Sistemas de Informação da Universidade Federal Fluminense para que a comunidade da área possa fazer uma avaliação do papel desempenhado por esta formação junto a sociedade e das possibilidades de atuação no sentido de contribuir com o melhoramento das condições de vida pela democratização do acesso ao conhecimento e à profissão. Ao mesmo tempo também pretende-se que esta reflexão sobre profissãosociedade contribua na conformação da identidade do campo de Sistemas de Informação. Este trabalho indica que responsabilidade social e Sistemas de Informação são conceitos indissociáveis, e portanto, devem constituir uma prática conjunta a se iniciar já na elaboração do próprio curso. 
Sistemas de Informação é uma área que se estabelece no estudo da concepção, implantação e operação de sistemas computacionais nos mais diversos ambientes: escolas, empresas, organizações governamentais, etc. Assim, construir sistemas que atendam satisfatoriamente a suas demandas pressupõe o conhecimento das dinâmicas e entraves desses ambientes. É preciso vivenciar as questões locais para elaborar soluções com elas (e não para elas) e, a partir dessa operação conjunta, construir sistemas que se ponham a favor das comunidades, contribuindo para a melhoria da qualidade de vida local.

Responsabilidade social significa o amplo reconhecimento por parte das corporações de seu papel transformador na sociedade. Da mesma forma e no mesmo grau, significa também o reconhecimento por parte das corporações do papel transformador que a sociedade local opera sobre ela. Assim, não se tratam de ações da corporação em benefício da sociedade, mas da constatação de que localidadecorporação constituem um corpo único com implicações mútuas. Daí, o bom funcionamento da corporação depende e condiciona o bem-estar da localidade.

Sendo o reconhecimento da sociedade uma questão determinante na efetivação das pesquisas no campo de Sistemas de Informação e na efetivação dos próprios sistemas, a compreensão da responsabilidade social necessita ser mais do que um conceito a ser ensinado. Precisa ser prática inerente à forma de pensar e agir daqueles que virão a ser os produtores das tecnologias em Sistemas de Informação. Na próxima seção passamos a descrever o processo de construção do curso de Sistemas de Informação da Universidade Federal Fluminense relatando os avanços e retrocessos com relação ao reconhecimento da conjuntura social.

\section{A construção do Bacharelado em Sistemas de Informação}

\subsection{Algumas palavras sobre as estratégias desta pesquisa}

A abordagem chamada "Cartografia das Controvérsias" [Latour, 2012] foi pensada no âmbito da Teoria Ator-Rede para auxiliar a explorar e visualizar polêmicas e controvérsias. Segue a orientação minimalista da Teoria Ator-Rede de basear-se em poucas diretivas de trabalho e operar no fluxo e na dinâmica dos acontecimentos ao invés de estabelecer um arcabouço teórico a ser tomado como trilho. Essa perspectiva é alcançada através de uma abordagem situada, o que significa priorizar as coisas do local e momento onde a controvérsia se desenrola, além de uma postura comprometida do pesquisador, que nunca se coloca como um observador imparcial com relação à controvérsia pesquisada, ao mesmo tempo em que se esforça por ampliar o espaço de fala, abrindo espaço a diferentes pontos de vista. Essas duas diretivas implicam na impossibilidade de produzir um veredito fechado e definitivo, e também implicam na presença de atores inusitados, que não fariam parte dos estudos usualmente considerados científicos, mas que se fazem presentes nos acontecimentos.

A Cartografia das Controvérsias busca dar luz às relações de forças que se estabelecem numa controvérsia. Neste estudo, a cartografia nos auxilia no mapeamento das seguintes tensões: (i) a compreensão do campo da computação como ciências exatas e a ameaça do acolhimento de identidade híbrida, mesclada com áreas humanísticas, (ii) a compreensão da computação como campo de formação "científica" e a ameaça de uma formação voltada para a lógica do trabalho. Ressaltamos aqui que o curso foi criado num departamento que já acolhia um curso de Ciências da Computação (ciências exatas) considerado bem-sucedido e em operação há pelo menos 3 décadas. Nesse 
cenário, relatamos os motivos da escolha da formação em Sistemas de Informação como novo curso no departamento, os embates, negociações, retrocessos, chegando à situação atual.

Além da Cartografia das Controvérsias utilizamos também a abordagem "pesquisarCom", proposta por Márcia Moraes [2010], no campo dos estudos em psicologia. Também situada no âmbito da Teoria Ator-Rede essa abordagem tem sua motivação na busca por uma direção de pesquisa que opere na lógica do "e", e não do "ou", ou seja, que permita operar no encontro das diferenças e não seja excludente. No escopo deste trabalho, a proposta de pesquisarCom é interessante porque permite desestabilizar papéis muito firmemente estabelecidos e motiva a re-elaborar estes papéis no fluxo das relações de cooperação que se desenvolvem coletivamente. PesquisarCom desestabiliza o papel do pesquisador no campo da psicologia como aquele que intervém, aquele que desencadeia uma ação sobre o outro. Aqui, de forma semelhante, nos interessa desestabilizar o papel do professor como aquele que fala/ensina/transmite e do aluno quem escuta/aprende/recebe passando a considerar uma relação de co-construção, uma construção no encontro desses atores. Da mesma forma, interessa hibridizar as funções de organização do curso de modo a conceber espaços de co-produção onde seja possível que o discente participe das decisões que lhe afetam.

Assim como a Cartografia das Controvérsias, PesquisarCom exige numa atitude situada, ou seja, sempre aderente aos acontecimentos e suas diversas falas, o que torna fundamental a adoção de procedimentos de coleta de informação, levantamento de dados e, principalmente, escuta.

\subsection{Ponto de partida}

O curso de Sistemas de Informação da Universidade Federal Fluminense foi criado no contexto do Programa de Apoio a Planos de Reestruturação e Expansão das Universidades Federais [MEC,2003] que tinha como principal objetivo ampliar o acesso e a permanência na educação superior. Este programa contempla o aumento de vagas nos cursos de graduação, a ampliação da oferta de cursos noturnos, a promoção de inovações pedagógicas e o combate à evasão, dentre outras metas que têm o propósito de diminuir as desigualdades sociais no país. O REUNI foi instituído pelo Decreto $\mathrm{n}^{\circ}$ 6.096, de 24 de abril de 2007 [BRASIL, 2007], e é uma das ações que integram o Plano de Desenvolvimento da Educação [MEC, 2007].

O Conselho Universitário da Universidade Federal Fluminense (UFF), por meio da indicação 06/2007, publicada em 29 de agosto de 2007, apontou às diversas unidades da UFF que promovessem amplo debate sobre o REUNI. Em dezembro de 2007 a UFF aprovou a adesão ao Programa REUNI. Em março de 2008 o programa retornou como assunto na pauta de reunião do Instituto de Computação, com exposição de alguns professores. Uma consequência da adesão ao REUNI foi abertura e expansão de diversos cursos na universidade. Cabe aqui salientar uma particularidade da UFF: o seu caráter de interiorização. A UFF se espalha por diversos municípios do Estado do Rio de Janeiro e a comunidade acadêmica tem orgulho deste papel de interiorização. Assim, surgiram diversas propostas de implantação de cursos pelo estado. Em particular, na área da computação, surgiu a proposta de implantação do curso de Computação no município de Santo Antônio de Pádua que mais tarde se tornaria o curso Licenciatura em Computação. Na mesma ocasião surgiram outras propostas diretamente relacionadas à área de computação no Instituto de Matemática: um curso de pós-graduação em Desenvolvimento de Software em Software Livre e ainda a incorporação do nome 
"Segurança em Redes" a um curso já existente de Criptografia. Já havia, naquele momento, o curso de Ciência da Computação do município de Rio das Ostras, desvinculado do Instituto de Computação. Este contexto demonstra a configuração de um ambiente de certa pressão por um posicionamento mais firme do Instituto de Computação, tanto no sentido de reafirmar-se como principal ator no que toca o ensino na área de Computação na UFF como na necessidade de um posicionamento mais decisivo com relação ao REUNI.

Em julho de 2008 a direção do Instituto de Computação publicou uma determinação de serviço (DST TIC, Nº 05 de 02 de julho de 2008) onde se designou uma comissão para realizar levantamento dos Cursos de Graduação em Computação no âmbito das Sociedades Científicas que congregam os profissionais dessa área, nacional e internacionalmente, entre as quais a Sociedade Brasileira de Computação (SBC), e propor, no prazo de quarenta e cinco dias, a criação de Curso(s) ao Instituto de Computação. Além disso, a comissão deveria realizar levantamento dos currículos de referência pertinentes, propor adaptações apropriadas e redigir a proposta de criação de Curso(s) de Graduação, acompanhada do perfil do egresso, cronograma de implantação, demanda por novos docentes e outros requisitos identificados, no prazo estipulado. Tal levantamento foi apresentado na reunião do colegiado do Instituto do dia 24 de setembro de 2008, com bastante aderência aos propósitos de contribuir na minimização das diferenças sociais e também com vistas a reduzir as taxas de evasão e abandono, e as dificuldades de acompanhamento já demasiadamente altas no curso de Ciência da Computação. Cabe relembrar que os programas sociais de ingresso na UFF vinham sendo implementados de acordo com os planos do governo brasileiro sem que houvesse uma preocupação efetiva com a criação de mecanismos nas universidades para garantir a permanência dos alunos ingressantes. "[D] emocratização de acesso e mecanismos de permanência são questões que devem ser abordadas colateralmente. Mecanismos de permanência devem ser fundamentados na capacitação dos alunos para acompanhar os cursos de maneira satisfatória" [Cafezeiro,2006]. Seguindo a terminologia adotada pela SBC, a comissão defendeu a viabilidade de um curso que teria a "computação como meio" e propôs o curso de Sistemas de Informação, no horário noturno, justificando-o tecnicamente.

\subsection{Surge um curso de computação como "atividade meio" e horário noturno}

"Computação como meio" é um termo utilizado pela SBC em documentos como o currículo de referência em computação. O termo designa cursos em que os egressos serão "capacitados a aplicar a computação em outros domínios de conhecimento" com vistas a resolver "problemas organizacionais ou administrativos" nos diversos contextos: "industriais, de prestação de serviços, de consultoria, empresas públicas e estatais, empresas produtoras de software, etc" [SBC, 1999]. Em oposição, cursos em que a computação é abordada de forma dissociada de seus contextos de operação são classificados como cursos que tomam a computação como "atividade fim". Esta divisão entre "atividades meio" e "atividades fim" parece ter sido sedimentada no Brasil a partir da década de 1970, em uma proposta educativa brasileira escrita para estrangeiros, publicada no Congresso Internacional de Processamento de Informação, IFIP [Lucena, 1975]. Esta divisão sela a separação entre as atividades da computação que tornam visível o contato com a sociedade e aquelas em que a computação parece resumir-se a questões técnicas. Nos dias de hoje as abordagens sociotécnicas fazem uma crítica a esta cisão entre sociedade e técnica [Cafezeiro, Costa, Kubrusly,2016]; Cukierman, Teixeira \& Prikladnicki, 2007; Woolgar, 1991] em função das evidências da impossibilidade da 
"técnica", por si só, dar conta das questões a que se propõem. Dito de outra forma, as abordagens sociotécnicas duvidam da existência de algo que seja puramente "técnico" ou puramente "social" e argumentam que esta caracterização situa os cursos ditos de "atividade meio" em posição desprestigiada, como cursos não científicos, por focarem a formação de egressos para o mercado de trabalho.

A escolha de um curso de "computação como meio" foi motivada por uma demanda discente interna que se fazia visível na procura por projetos de fim de curso em áreas de desenvolvimento em sistemas de informação, aproximando-se mais do mercado de trabalho. Havia também uma demanda externa percebida pela existência de muitos profissionais em atividade no mercado que buscavam a formação acadêmica correspondente. Para atender a essas demandas interna e externa, e também à conjuntura nacional que dava visibilidade às ações com desdobramentos no campo social seria fundamental que o curso então vislumbrado pudesse ser cursado concomitantemente com o trabalho: situações do trabalho poderiam trazidas para âmbito acadêmico atendendo à demanda interna, e os profissionais em atividade teriam acesso ao estudo atendendo à demanda externa. A escolha do horário noturno teve um papel de destaque na concepção da proposta por favorecer as demandas sociais: a) não havia curso de Sistemas de Informação totalmente noturno, em instituição pública no estado, se constituindo um diferencial na região do estado do Rio de Janeiro; b) a orientação do REUNI priorizava cursos noturnos de modo a atender à parcela da população trabalhadora; c) a possibilidade de atender a todo um grupo de pessoas que estavam no mercado e não tinham possibilidade de terminar sua graduação ${ }^{2}$. Mas a aceitação do horário noturno pelos docentes do departamento deveu-se ao indicativo de evitar o conflito com o curso diurno existente e ainda amenizar alguns de seus gargalos: a) evitar o risco de congestionar os laboratórios do Instituto de Computação utilizados pelos alunos do curso de Ciência da Computação; b) a possibilidade de que as disciplinas de Sistemas de Informação fossem usadas pelos alunos de Ciência da Computação com dificuldades de integralização curricular. Após quatro meses de trabalho a comissão de implantação apresentou o resultado, o plano pedagógico do curso de Sistemas de Informação, que deixava claro o compromisso com demanda social:

Em nível nacional existem diversos cursos de graduação em Sistemas de Informação fortemente calcados nos pressupostos do currículo de referência da SBC. A título de exemplo, citamos os cursos da UFMG, UNICAMP, USP e UNESP. A criação destes cursos é recente e justifica-se sobre números da SBC: estima-se que o mercado necessite de $50 \%$ a $75 \%$ de egressos desses cursos sobre o total de egressos necessários para o mercado de computação. Ainda, em nível nacional, verifica-se o oferecimento destes cursos no turno vespertino ou noturno, o que se justifica pelo atendimento a uma parcela da população com inserção imediata no mercado de trabalho. [Lima et al, 2009]

\footnotetext{
${ }^{2}$ São pelo menos dois os motivos que justificam a presença de grande presença de profissionais não graduados no mercado. $O$ primeiro é o fato de que a criação dos cursos de computação é relativamente recente com relação ao trabalho na área. O segundo consiste no interesse por parte da comunidade em informática de que haja certa liberdade de formação devido ao caráter múltiplo da profissão. Esses motivos estão explicitamente mencionados nas justificativas do projeto de lei que regulamenta a profissão [BRASIL, 2003].
} 


\title{
3.4. Recusas, objeções: desvios na proposta original
}

\begin{abstract}
O Curso de Graduação em Informática: Sistemas de Informação da UFF será oferecido em horário noturno e pretende contar com grande flexibilidade curricular, além da utilização de metodologias semipresenciais, mediadas por computador. Estes fatores, além de permitirem um melhor aproveitamento das instalações físicas, também visam alcançar uma parcela da população não atendida pelo atual curso de Bacharelado em Ciência da Computação, que opera nos turnos da manhã e tarde. [Lima et al, 2009]
\end{abstract}

Fica claro no trecho acima que havia uma necessidade de conciliação dos compromissos sociais com as expectativas de sucesso e desenvolvimento do curso então existente Ciência da Computação. O novo curso deveria atender às recomendações dos docentes de que houvesse um núcleo comum em que as disciplinas fossem dadas nos mesmos moldes e com os mesmos pré-requisitos de modo a atender também aos alunos do curso de Ciência da Computação (diurno). O propósito de atender "uma parcela da população não assistida pelo curso de Ciência da Computação" se dirigia aos alunos evadidos/jubilados de diversos cursos de Tecnologia da Informação (inclusive do próprio curso de Ciência da Computação). Muitos destes alunos possuíam larga experiência no mercado e sua inserção no curso de Sistemas de Informação era esperada, principalmente pela possibilidade de troca experiência academia-mercado. $\mathrm{O}$ horário noturno foi aceito pelos docentes como uma questão estratégica por abrir a possibilidade de que disciplinas de Sistemas de Informação fossem usadas pelos alunos Ciência da Computação que por estarem trabalhando tinham dificuldades de integralização curricular. De fato, a partir da criação do curso de Sistemas de Informação, o curso de Ciência da Computação alterou o seu turno manhã/tarde para integral disponibilizando as disciplinas noturnas para seus alunos. Em termos numéricos, a quantidade de ex-alunos do curso Ciência da Computação chegou a alcançar a proporção de $27 \%$ das vagas ocupadas pelos alunos aprovados no ENEM/SISU, em ampla concorrência, no segundo período de 2015.

O fato do curso ser noturno não chegava a ser uma preocupação dos docentes. Ao contrário disso, era esperado que complementasse a formação de alunos de Ciência da Computação. Além disso, os professores entendiam que contrações futuras dariam conta do horário noturno, de maneira que eles próprios não ficariam encarregados de estar presentes no horário noturno. Naquele momento, a preocupação maior era vislumbrar quem seria o professor de Sistemas de Informação, qual seria o perfil desse profissional a ser recebido no quadro docente do departamento. A ideia que esse profissional poderia não ter formação em Ciência da Computação talvez tenha sido o maior problema enfrentado pelo curso.

Assim, percebemos que o acolhimento da área de Sistemas de Informação pelo departamento foi apenas parcial. A implantação do curso se concretizou para atender as exigências da universidade com relação ao REUNI e foi construída de modo a amenizar as sobrecargas locais do curso de Ciências da Computação. Como consequência, a primeira grade curricular do curso de Sistemas de Informação não contou com as disciplinas de caráter especifico para formação de um profissional de Sistemas de Informação que constavam no currículo de referência da SBC, tais como: Modelagem de Processo de Negócio, Governança de Tecnologia da Informação, Qualidade de Software, Teste de Software, Auditoria de Sistemas, entre outras. A grade resultante mais parecia a grade de um curso de Ciências da Computação noturno sem Física e pouca Matemática, com as disciplinas do departamento minimamente refletidas e 
oferecidas para um "Ciências da Computação noturno". Acompanhando tendência do departamento de não discutir o perfil do professor das disciplinas específicas de Sistemas de Informação, não houve a criação de um novo departamento que pudesse acolher o novo perfil e implantar o curso, o que seria natural e esperado, em razão da própria legislação da UFF que preconiza a criação/desdobramento de departamentos para acompanhar a criação de cursos novos ${ }^{3}$.

\subsection{O fortalecimento de vínculos com o campo de Sistemas de Informação}

Decorridos cinco anos de funcionamento, a distorção curricular vem sendo corrigida ao longo do tempo e às custas de muito debate, reforma curricular e alterações pontuais. A contratação de professores com o perfil específico de Sistemas de Informação ainda encontra forte resistência por parte dos docentes, apesar de ser explícita esta demanda pela rotina de turmas sem professores e áreas descobertas.

Apesar destas dificuldades, é visível no corpo discente uma forte característica de participação e colaboração nas situações de conflito. Este comportamento possivelmente advém de fatores como a presença constante de conteúdos humanísticos que fomentam o debate, a ação e a atitude crítica; a percepção de que o curso não se apresenta como um corpo consolidado, sendo frequente o apelo à participação discente e a escuta à opinião dos alunos; a perceptível assimetria com relação ao curso de Ciência da Computação no que diz respeito à alocação de professores (o curso recebeu grande número de professores substitutos ao longo de sua existência), monitores (ausência de alocação de monitores em horário compatível) e recursos (problemas com o horário de funcionamento); a perceptível atitude de desprestígio por parte de grande parte da comunidade docente e discente que considera o curso mais fraco do que o curso de Ciência da Computação pela presença das disciplinas humanísticas [Cafezeiro, Viterbo, Costa, Salgado, Rocha, Monteiro, 2017,Cafezeiro, Costa, Kubrusly, 2016]. Talvez seja esta identidade dos discentes com relação ao curso o principal motivo dos resultados positivos que surpreenderam os docentes do Instituto. Atualmente, com cinco anos de funcionamento o curso, já coleciona alguns índices de sucesso, como a nota 4.0 na avaliação do MEC em 2016 (não foi 5.0 por questões de infraestrutura), a nota 5.0 no Exame Nacional de Desempenho de Estudantes (ENADE) em 2014, sendo único curso da UFF, em Niterói, a alcançar essa pontuação, a ativa participação anual docente e discente em eventos da área, como o Simpósio Brasileiro de Sistemas de Informação, tendo inclusive sediado $a$ Primeira Escola Regional em Sistemas de Informação (http://www2.ic.uff.br/ ersirj/), e a aceitação de diversos alunos em cursos de pósgraduação no Brasil e no exterior, bem como o excelente acolhimento no mercado de trabalho. No entanto, ainda hoje, acompanhando a resistência dos docentes do departamento em acolher com o perfil específico de Sistemas de Informação, é ampla a recusa docente em ministrar aulas nos horários noturnos. Não há ainda no Instituto um departamento que adote regras e mecanismos que favoreçam o modo de atuar do curso e não há ainda uma pós-graduação que se dedique as pesquisas do campo. Estes últimos fatores se devem especialmente ao reduzido número de docentes atuantes no campo aliado ao fato de que as decisões são tomadas por votação.

\footnotetext{
3 Pelo artigo segundo da resolução número 90/95 da UFF, que normatiza a criação departamentos de ensino, a "criação de departamento de ensino ocorre quando é organizado um conjunto de docentes em uma determinada área de conhecimentos (...) a partir da instituição de um curso de graduação (...)".
} 
Um recente clamor docente pelo fim do curso noturno a despeito de todo o compromisso social provocou a revolta de alguns professores atuantes no curso de Sistema de Informação acompanhados de grande contingente de alunos. Este episódio desencadeou o levantamento dos dados que serão brevemente apresentados na seção seguinte. Uma versão estendida e detalhada destes dados foram organizadas na forma de relatório e entregues ao Instituto de Computação permitindo verificar que os ajustes feitos na grade curricular e o funcionamento atual do curso seguem as indicações das entidades reguladoras da área no que se referem ao campo de Sistemas de Informação, e que, apesar do percurso de descaracterização da proposta de modo a remediar as deficiências do curso de Ciência da Computação, a operacionalização do curso de Sistemas de Informação se mantêm aderente ao compromisso social assumido desde o início. A seguir, reproduzimos parte dos dados apresentados aos docentes do Instituto de Computação para reiterar a efetivação das estratégias sociais adotadas, incluindo-se o horário noturno.

\section{Evidências do compromisso com a demanda social}

\subsection{Um breve Perfil do Aluno de Sistemas de Informação}

Observando as idades dos alunos de Sistemas de Informação verificamos uma distribuição por todas as faixas etárias com número razoável de pessoas entre 20-27 anos, sendo que $10 \%$ dos alunos estão acima dos 31 anos. Este dado é um indicador de que o curso atende à parcela de trabalhadores ativos no mercado de trabalho. Algumas disciplinas, como Computação e Sociedade, estabelecem o diálogo direto com/entre os estudantes de modo a efetivar trocas de experiências. Através dos relatos em sala de aula pode-se verificar que este contingente estudantes-trabalhadores provém do campo de Sistemas de Informação. Desta maneira, o compromisso social de atender a esta demanda reverte em favor do próprio curso possibilitando um canal de debates a partir das experiências vividas no mercado de trabalho.
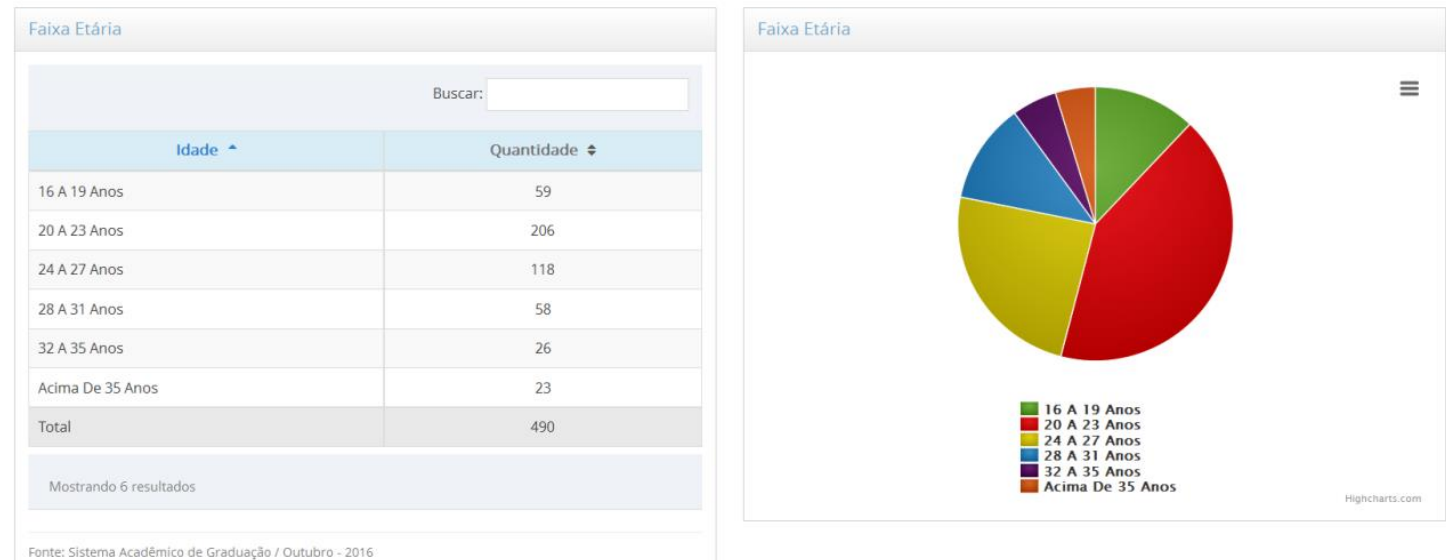

Figura 1: Distribuição por Faixa etária - Sistemas de Informação (Fonte: https://sistemas.uff.br/transparencia/perfil graduando, em dezembro 2016)

Ao comparar com os alunos de Ciência da Computação verificamos uma maior concentração nas primeiras faixas etárias e com quase o dobro de alunos (117) na primeira faixa (16-19 anos) se comparada com Sistemas de Informação (59 alunos). Isso aponta para uma população de alunos mais velhos em Sistemas de Informação, muitos trazendo, conforme esperado, a experiência no mercado de trabalho. É, também, um indicador de que uma boa parte de alunos de Ciência da Computação está vindo 
diretamente do Ensino Médio, enquanto os de Sistemas de Informação podem ter finalizado o Ensino Médio a mais tempo, ou ainda, são evadidos de outros cursos.
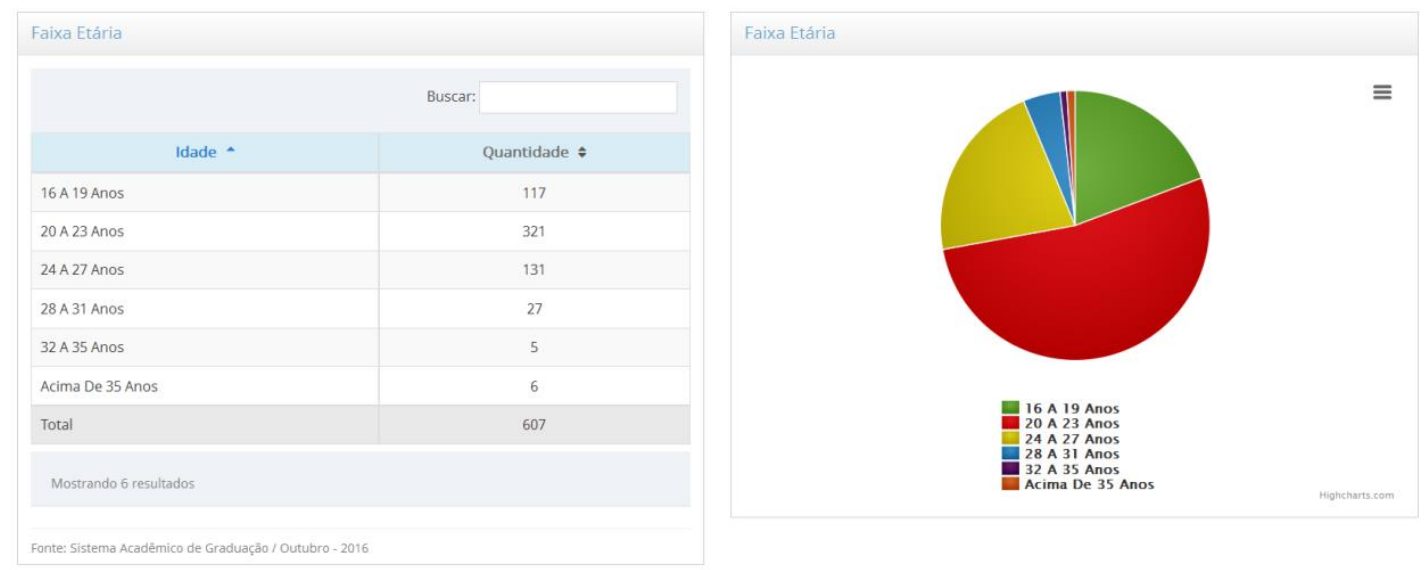

Figura 2: Distribuição por Faixa etária - Ciências da Computação (Fonte: https://sistemas.uff.br/transparencia/perfil graduando, em dezembro 2016)

A coordenação do curso de Sistemas de Informação realiza desde o segundo período de 2013, no ato da inscrição de disciplinas, uma pesquisa com os alunos para averiguar a pertinência do horário noturno. Em um total de 284 alunos respondentes, $68 \%$ aponta o horário noturno como o motivo pela escolha do curso, uma vez que possibilita o trabalho diurno. Um total de $45 \%$ relatou estar trabalhando. Quando perguntados se pretendem trabalhar durante o curso foram obtidas $92 \%$ de respostas afirmativas. Novamente, a presença do aluno-trabalhador contribui na formação de um diálogo direto do aluno em formação com o mercado de trabalho. Mais uma vez ressaltamos que há o estímulo para que essas experiências sejam relatadas e amadurecidas em sala de aula, assim como ocorre o aproveitamento destas experiências nos trabalhos de conclusão de curso.

Outras estatísticas que podem também ser verificadas no sítio de transparência da universidade (https://sistemas.uff.br/transparencia/perfil_graduando) são indicadores da amplitude geográfica abrigada pelo curso incluindo regiões de vulnerabilidade social, da busca pela democratização em gênero e etnia. De modo geral, os alunos de Sistemas de Informação são na grande maioria oriundos de Niterói e municípios próximos como São Gonçalo e Rio de Janeiro, porém muitos deles se deslocam de diversos outros municípios: Duque de Caxias, Mesquita, Barra do Piraí, Magé, Paracambi, Belford Roxo, Maricá, São Pedro da Aldeia, Guapimirim, Cachoeiras de Macacu, Itaboraí, Barra Mansa, Rio Bonito, Volta Redonda, Quatis, Nilópolis, Iguaba Grande, Nilópolis, Miguel Pereira, Bom Jesus do Norte, Nova Iguaçu, Itaperuna, Araruama. O curso apresenta uma percentagem de negros e mulheres superior à do curso de Ciência da Computação.

\subsection{A Oferta de Vagas}

Atualmente o curso oferece 61 vagas, dentre a percentagem de cotas e a ampla concorrência, em cada semestre. Essas vagas têm sido preenchidas em sua grande maioria e a procura pelo curso tem deixado a relação candidato vaga em média em 20,81, segundo dados da Coordenação de Seleção Acadêmica (www.coseac.uff.br). O curso recorre à outras formas de ingresso, como transferências e reingresso, para compensar a perda de vagas que é inerente ao processo de inscrição da UFF. 


\subsection{Sistemas de Informação e Ciência da Computação.}

Como dito anteriormente, o curso de Sistemas de Informação procura atender a uma parcela da população do estado não assistida pelo curso de Ciência da Computação e de certa forma uma boa parte dessa população é de alunos evadidos do curso de Ciência da Computação. Porém, Sistemas de Informação não impacta positivamente somente sobre essa população. Os alunos ativos são beneficiados pela disponibilização de disciplinas noturnas. Do primeiro período de 2012 até o segundo período de 2016 (10 semestres) os alunos de Ciência da Computação ocuparam 1262 vagas nas turmas de Sistemas de Informação. Do total de 68 alunos formados em Ciência da Computação, a partir do primeiro período de $2014,87 \%$ desses alunos utilizaram disciplinas noturnas para a integralização curricular.

\subsection{O Egresso}

O curso de Sistemas de Informação diplomou 18 alunos no primeiro período de 2016. Esse número é considerado baixo pela coordenação, porém, todos os alunos se formaram com coeficiente de rendimento maior do que 7,0 sendo que alguns deles estão fazendo pós-graduação. Um deles recebeu o Prêmio Láurea Acadêmica. O baixo número de diplomados, até agora, pode ser explicado ao avaliar o número médio de disciplinas cursadas por período. Embora a grade possua em média 5 disciplinas por semestre, os alunos cursam 3 disciplinas (em média).

\subsection{O conceito de "aluno equivalente"}

"Aluno equivalente" é o principal indicador utilizado para fins de análise dos custos de manutenção das Instituições Federais de Educação Superior (IFES) nas rubricas referentes ao orçamento de custeio e capital. No cálculo do aluno equivalente é dado um bônus de $15 \%$ para os cursos noturnos e de $10 \%$ para os cursos ministrados fora da sede da IFES. Cada vaga preenchida significa em 2016 vale $\mathrm{R} \$ 2988,915$. Uma comparação com outros cursos de computação da UFF nos anos de 2014 e 2015, indica o quanto o aluno do curso de Sistemas de Informação impacta a universidade em termos do recebimento de verbas federais: Em 2014 o aluno de Sistemas de Informação valia 469,2000, enquanto que o aluno de Ciência da Computação em Niterói valia 451,9800 e em Rio das Ostras 318,5500. Já em 2015, o aluno de Sistemas de Informação valia 608,9250, enquanto que o aluno de Ciência da Computação em Niterói valia 500,1600 e em Rio das Ostras 75,1245. Esses dados confirmam o incentivo do Governo Federal aos cursos noturnos preconizado pelo REUNI, e mostram que uma possível mudança de turno afetaria a matriz orçamentária da UFF.

\section{Conclusões}

\subsection{Contribuições da trajetória descrita para a identidade do campo de Sistemas de Informação}

No âmbito acadêmico, onde se configuram os currículos universitários, a compreensão de que sistemas devem ser desenvolvidos em co-participação com a sociedade tem se fortalecido, mas ainda não é consensual. Na década de 1990, o que justificou a caracterização de um novo currículo que recebeu o nome de "Sistemas de Informação" foi o enfoque na gestão [Ferreira, Silva, Neto, 2000] uma abordagem que foi também acolhida no campo da Administração [Albuquerque, Prado, Coelho e Celso, 2011]. Este enfoque permitiu reforçar o caráter tecnicista dos currículos em discussão: 
Ressalta-se que essa identidade do curso de BSI [Bacharelado em Sistemas de Informação] só pode advir, de fato, de conteúdos programáticos de SI [Sistemas de Informação], os quais deveriam consolidar o supramencionado perfil interdisciplinar do curso entre os campos do saber da Computação e da Administração (da Informação) [Albuquerque, Prado Coelho e Celso, 2011, p.1].

Esta visão facilitou a permanência de Sistemas de Informação como um subcampo das Ciências da Computação, conforme consta hoje nas tabelas das áreas de conhecimento do $\mathrm{CNPq}$, pela aderência às ciências exatas. A ênfase no caráter tecnicista também se fortaleceu nos documentos da Sociedade Brasileira da Computação [SBC,1999], que organiza os conteúdos programáticos em seis categorias (Fundamentos da Computação, Tecnologia da Computação, Sistemas de Informação, Matemática, Ciências da Natureza, Contexto Social e Profissional), e as disciplinas destas seis categorias são demarcadas como "atividades fim" e/ou "atividades meio". Entretanto, as disciplinas marcadas como atividades meio são claramente um subconjunto das outras, com a exceção de apenas seis exclusivas das atividades meio (Controle e Avaliação de Sistemas, Gerência de Projetos, Gestão da Informação, Sistemas Cooperativos, Contabilidade e Custos e Métodos Quantitativos Aplicados à Administração de Empresas), em contraponto às dezoito disciplinas exclusivas das atividades fim. Se a graduação em Sistemas de Informação traz a marca da atividade meio, fica claro aqui que a área é estabelecida como um subconjunto da formação em Ciências da Computação, o que prejudica a formação da identidade de Sistemas de Informação. Dizem Albuquerque, Prado Coelho e Celso [2014, p.89] que: "muitas vezes a comunidade acadêmica parece entender o BSI apenas como um curso de Ciência da Computação menos teórico ou com maior aplicação, ou seja, sem identidade própria positiva, mas apenas diferenciando-se negativamente de outros cursos da área de Computação e Informática". De fato, é isto o que indicam as Diretrizes do MEC: "Esses cursos reúnem a tecnologia da computação e a tecnologia da administração e, portanto, possuem, de ambas as áreas, um enfoque pragmático forte e pouco teórico" [MEC, 1999, pg19].

Mas, alguma coisa mostra que esse papel de desprestígio com relação às Ciências da Computação não se efetiva na prática, porque embora não tenha sua identidade contemplada nos documentos oficiais, o campo de Sistemas de Informação vem se fortalecendo ao longo dessas três décadas. Albuquerque, Prado Coelho e Celso [2014] observam que "as matrizes curriculares dos cursos de BSI no Brasil diferem largamente das proporcionalidades estipuladas pelo referencial da Sociedade Brasileira de Computação" [Albuquerque, Prado Coelho e Celso, 2014,p. 88] e que, referindo-se às seis categorias de disciplinas propostas pela SBC, "os cursos de BSI no geral têm proporcionalmente menor carga de Sistemas de Informação e maior carga de Contexto Social e Profissional" [Albuquerque, Prado Coelho e Celso, 2014, p. 88]. Isto mostra que, embora não haja o reconhecimento por parte das instâncias que propõem as diretrizes curriculares, há na prática o reconhecimento da importância da coparticipação de estudos sociais nestes currículos. Por este motivo, o que é chamado de "Contexto Social e Profissional" no Currículo de Referência da Sociedade Brasileira de Computação deveria ser incorporado ao núcleo da área de Sistemas de Informação. Fazer o contexto virar texto. Isto significa que sociedade e profissão se misturam com aquilo que se diz que seria dito "técnico" na formação de um campo de saber, em particular, em Sistemas de Informação. Nessa direção, a despeito das indicações dos documentos oficiais, a área de Sistemas de Informação vai afirmando sua identidade 
como um campo interdisciplinar, que tem a sua identidade na co-participação da sociedade e tecnologia, tem como uma das suas bases teóricas a compreensão deste processo de co-participação. A partir daí, a área vem, na prática, definindo suas disciplinas pelo reconhecimento das demandas da conjuntura local e atual.

\subsection{Considerações finais}

No artigo "Educação e apropriação da realidade local" o economista Ladislau Dowbor (2007) apresenta algumas questões relacionadas à educação e gestão do conhecimento no sentido da construção de uma abordagem local da educação. Isto significa um afastamento com relação às metodologias, mecanismos e currículos universalmente consolidados e amplamente aceitos e uma maior aproximação às localidades. Maior autonomia aos municípios, formação de núcleos de apoio, participação de atores locais são questões que passam a figurar na construção de uma proposta educativa situada no tempo e no espaço. $\mathrm{O}$ artigo de Dowbor não focaliza a educação superior, mas algumas de suas análises se aplicam à educação em qualquer nível, incluindo-se aí a educação de adultos em termos gerais. Destacamos aqui alguns pontos que se fizeram evidentes na instalação do curso de Sistemas de Informação da UFF que desde o início buscava um forte compromisso social. O primeiro ponto diz respeito à interdisciplinaridade e flexibilização dos currículos. Dowbor mostra que as rápidas transformações do mundo em que vivemos demandam dinâmica e flexibilidade que não são possíveis nos currículos amarrados por disciplinas e fronteiras do conhecimento:

[T]orna-se cada vez mais fluida a noção de área especializada de conhecimentos, ou de "carreira", quando do engenheiro se exige cada vez mais uma compreensão da administração, quando qualquer cientista social precisa de uma visão dos problemas econômicos, e assim por diante, devendo-se, aliás, colocar em questão os corporativismos científicos;

Daí a necessidade de ultrapassar as fronteiras rigidamente estabelecidas, aprender a trabalhar no encontro dos diversos saberes (no campo da computação, os ditos exatos e os ditos humanísticos) transpassando as demarcações das grandes áreas bem como as separações ensino-trabalho. Daí, o segundo ponto que Dowbor ressalta:

[A]profunda-se a transformação da cronologia do conhecimento: a visão do homem que primeiro estuda, depois trabalha, e depois se aposenta torna-se cada vez mais anacrônica, e a complexidade das diversas cronologias aumenta;

É portanto necessário e urgente acolher o estudante-trabalhador. Isto se dá não somente no sentido de viabilizar a presença do trabalhador em sala de aula através do horário noturno. Nosso percurso nestes primeiros anos de operação do curso de Sistemas de Informação mostra que é preciso reivindicar a atuação participativa destes estudantestrabalhadores de modo a trazer para a sala de aula questões relativas à sua atuação no mercado de trabalho. Consegue-se a partir daí uma interação franca com a prática da profissão, possibilitando referências a situações vivenciadas no lugar dos usuais estudos de casos muitas vezes formatados para ilustrarem perfeitamente os métodos. Questão importante percebida em nosso percurso é que, ao contrário do que se pensa, o horário noturno representa uma melhoria de qualidade quando o trabalho é valorizado e inserido nas práticas educativas. Ao contrário do que se pensa, as aulas não são sonolentas, os 
estudantes não dormem devido ao cansaço da jornada de trabalho. Ao contrário disso, eles se manifestam e se percebem contribuintes. Daí, a terceira questão levantada por Dowbor:

[M]odifica-se profundamente a função do educando, em particular do adulto, que deve se tornar sujeito da própria formação, ante a diferenciação e riqueza dos espaços de conhecimento nos quais deverá participar;

Por fim, importa aqui ressaltar que a aproximação com as dinâmicas da vida (em particular, com o mercado de trabalho) não significa um afastamento com relação à pesquisa. Ao contrário disso, o que temos observado é a demanda crescente pela pesquisa devido a urgência de propor soluções a problemas emergentes. O campo de Sistemas de Informação vem apresentando à comunidade acadêmica um amplo e farto território de pesquisa, como mostra o documento dos Grandes Desafios em Pesquisa em Sistemas de Informação [Araújo, Maciel e Boscarioli, 2017].

Do que foi exposto neste artigo, vemos que a consideração das configurações sociais diz respeito à própria competência do profissional de Sistemas de Informação, já que os Sistemas são coletivamente construídos e postos a operar na sociedade. Daí fica clara a impossibilidade de separar as questões sociais das questões técnicas na formação profissional. Ademais, é clara a constatação de que a presença do aluno que trabalha em sala de aula oxigena e dinamiza práticas e conteúdos acadêmicos, desde que haja a disposição por parte da comunidade acadêmica em acolher e fazer circular estas vivências. A lei 13005 que aprova Plano Nacional de Educação estabelece em sua estratégia 12.3 para a educação superior elevar gradualmente a taxa de conclusão média dos cursos de graduação presenciais nas universidades públicas para 90\%, ofertar, no mínimo, um terço das vagas em cursos noturnos [BRASIL,2014]. A UFF atualmente atende minimamente esse dispositivo legal, ofertando $29,89 \%$ das suas vagas no período noturno.

A experiência do curso de Sistemas de Informação vem mostrando não somente as possibilidades no recebimento do estudante-trabalhador, mas também as vantagens nesse acolhimento como fator de melhoria da qualidade acadêmica. Para isso, o curso se empenha numa busca permanente de renovação de suas práticas participativas em sala de aula. Isto contribui para ressaltar um caráter interdisciplinar dos conteúdos apresentados, uma vez que os casos da vida são sempre interdisciplinares.

Ao longo do percurso aqui relatado, percebemos que, o diálogo com o mercado de trabalho, o horário noturno, a busca por mecanismos didáticos participativos, a interdisciplinaridade e a observação à realidade local são questões determinantes na formação do egresso em Sistemas de Informação. Esta formação só pode ser oferecida de maneira satisfatória a partir da compreensão das dinâmicas sociais e da constatação de que o curso precisa operar em co-operação (operação conjunta) com essas dinâmicas.

\section{Referências}

Albuquerque, J. P., Prado, E. P. V., Coelho, F. S, e Celso, R. P., (2011) Uma Análise da Abordagem Curricular do Ensino de Graduação em Sistemas de Informação no Brasil, Anais do II Encontro de Ensino e Pesquisa em Administração e Contabilidade.

Albuquerque, J. P., Prado, E. P. V., Coelho, F. S, e Celso, R. P., (2004) Educação em Sistemas de Informação no Brasil: Uma Análise da Abordagem Curricular em 
Instituições de Ensino Superior Brasileiras, Revista Brasileira de Informática na Educação, Volume 22, Número 1, 2014. doi: 10.5753/rbie.2014.22.01.79 [GS Search]

Araujo, R.M.; Maciel, R.S.; Boscarioli, C. (2017) "I GranDSI-BR: Grandes Desafios de Pesquisa em Sistemas de Informação no Brasil (2016-2026)" - Relatório Técnico. Comissão Especial de Sistemas de Informação (CE-SI) da Sociedade Brasileira de Computação (SBC). $\quad 67 p, \quad 2017 . \quad$ ISBN 978-85-7669-359-8. http://www2.sbc.org.br/ce-si//arquivos/grandsi.pdf

Ashenhurst, R. (1972) Curriculum Recommendations for Graduate Professional Programs in Information Systems. Commun. ACM 15 v. 5, p. 363-398. doi: $\underline{10.1145 / 355602.361320}$ [GS Search]

Ashenhurst, R. (1973) On the Problem of Characterizing Information Systems. Data Base v. 5, p. 148-156. doi: 10.1145/2579442.2579455 [GS Search]

Associação Brasileira de Normas Técnicas - ABNT NBR 16001:2004 p.3. http://www.inmetro.gov.br/qualidade/responsabilidade_social/norma_nacional.asp

Bernardes, A. G., Tavares G. M. \& Moraes, M. (2004) Cartas para pensar políticas de pesquisa em psicologia, Edufes, Vitória. [GS Search]

Bijker, W. E. \& Law, J. (1992) - Shaping Technology / Building Society: Studies in Sociotechnical Change, Cambridge, Massachusetts, The MIT press.

Bijker, Wiebe E. (1995). Of bicycles, bakelites, and bulbs: toward a theory of sociotechnical change. Cambridge, Massachusetts, The MIT press.

BRASIL (2003) Projeto de Lei 1561 de 2003. Dispõe sobre a regulamentação das profissões na área de Informática e suas correlatas e assegura ampla liberdade para o respectivo exercício profissional. Disponível em http://www.camara.gov.br/proposicoesWeb/fichadetramitacao?idProposicao=126039

BRASIL (2007) Decreto n ${ }^{\circ}$ 6.096, de 24 de abril de 2007. Institui o Programa de Apoio a Planos de Reestruturação e Expansão das Universidades Federais - REUNI. Disponível em http://www.planalto.gov.br/ccivil_03/_ato20072010/2007/decreto/d6096.htm.

BRASIL (2014) Lei $n^{\circ} 13.005$, de 25 de junho de 2014. Aprova o Plano Nacional de Educação - PNE e dá outras providências. Disponível em http://www2.camara.leg.br/legin/fed/lei/2014/lei-13005-25-junho-2014-778970publicacaooriginal-144468-pl.html.

Cafezeiro, i. 1.; Lima, R.; Murta, L. G.; Kischinhevsky, M. ; Clua, E. (2009) Projeto Pedagógico do Curso de Bacharelado em Sistemas de Informação. UFF.

Cafezeiro, I. (2006) Educação, Informática e Responsabilidade Social: A contribuição da Universidade Pública. In: Simpósio Brasileiro de Informática na Educação, 2006, Brasilia. Anais do SBIE 2006. http://br-ie.org/pub/index.php/sbie/article/view/462 [GS Search]

Cafezeiro, I., Costa, L. C. \& Kubrusly, R. (2016) "Modos contemporâneos de aprendizado e construção do conhecimento: reflexões sobre o ensino de Teoria da Computação para Sistemas de Informação", In: Anais do CSBC-WEI, pp. 22452254, PUCRS. http://ebooks.pucrs.br/edipucrs/anais/csbc/assets/2016/wei/26.pdf 
Cafezeiro, I., Viterbo, J., Costa, L. C., Salgado, L., Rocha, M., Monteiro, R. S. (2017). Strengthening of the Sociotechnical Approach in Information Systems Research, In: Grand Challenges in Information Systems Research in Brazil CE-SI SBC. http://www2.sbc.org.br/ce-si/arquivos/GranDSI-BR_Ebook-Final.pdf\#page=133

Costa, L. C., (2017) A Defesa do Curso. Relatório técnico apresentado ao Instituto de Computação da UFF sobre o curso de Bacharelado em Sistemas de Informação.

Cukierman, H.L.; Teixeira, C.; Prikladnicki, R. (2007) Um olhar sociotécnico sobre a engenharia de software. In: Rev. de Inf. Teórica e Aplicada, RS, UFRGS. http://www.seer.ufrgs.br/rita/article/viewFile/5696/3547 [GS Search]

Daston, L. e Galison, P. (2010) Objectivity. Zone Books, New York.

Davis, G.; Gorgone, J.; Couger, J.; Feinstein, D.; Longenecker, H. (1997) IS'97 Model Curriculum and Guidelines for Undergraduate Degree Programs in Information Systems. ACM/AIS/AITP. https://dl.acm.org/citation.cfm?id=2593308 [GS Search]

Davis, G.; Gorgone, J.; Valacich, J.; Topi, H.; Feinstein, D.; Longenecker, H. (2002) IS 2002 Model Curriculum and Guidelines for Undergraduate Degree Programs in Information Systems.

ACM/AIS/AITP. http://aisel.aisnet.org/cgi/viewcontent.cgi?article=2684\&context=cais [GS Search]

Dowbor, L. (2007) Educação e apropriação da realidade local. Estud. av. vol.21 no.60 São Paulo. doi: 10.1590/S0103-40142007000200006 [GS Search]

Ferreira, A.,Silva, D., Neto, G. L., (2000) Por um Referencial na Formação Profissional em Sistemas de Informação, Anais do VIII Workshop de Educação em Informática. http://www.lbd.dcc.ufmg.br/colecoes/wei/2000/008.pdf [GS Search]

Latour, B. (2012) Reagregando o Social. Uma introdução à teoria do Ator-Rede. São Paulo: EDUFBA e EDUSC.

Law, J (1997) Traduction/Trahison: Notes On ANT, published by the Department of Sociology, Lancaster University. Retrieved from http://www.lancaster.ac.uk/fass/resources/sociology-online-papers/papers/lawtraduction-trahison.pdf.

Law, J. and W.E. Bijker (2000) Shaping technology/building society: Studies in sociotechnical change. The MIT press.

Lucena, C. (1975) A multilevel national approach to computer education. P. 145-150. In: Lecarme, Olivier; Lewis, Robert (Eds.). Computers in education: proceedings of the IFIP 2d World Conference, International Federation for Information Processing. Amsterdam: North-Holland Publishing Company.

MEC (1999) Diretrizes Curriculares de Cursos da Área de Computação e Informática. ftp://ftp.inf.ufrgs.br/pub/mec/diretrizes.doc.

MEC (2003) Reuni - Programa de Apoio a Planos de Reestruturação e Expansão das Universidades Federais. Disponível em http://reuni.mec.gov.br/o-que-e-o-reuni.

MEC (2007) Plano de Desenvolvimento da Educação. Disponível em http://portal.mec.gov.br/arquivos/livro/livro.pdf. 
Moraes, M. (2010). Política ontológica e deficiência visual. In M. Moraes \& V. Kastrup (Orgs.). Exercícios de ver e não ver: arte e pesquisa com pessoas com deficiência visual (pp 26-51). Rio de Janeiro. Nau/Faperj.

Nascimento, J. (2016) Gestão Situada de Incubadoras Sociais. O caso da Incubadora Afro Brasileira. Editora Multifoco, Rio de Janeiro.

Porter, T. (1996) Trust in Numbers: The Pursuit of Objectivity in Science and Public Life. Princeton University Press.

SBC (1999) "Currículo de Referência da SBC para Cursos de Graduação em Computação". Sociedade Brasileira de Computação. Bento Gonçalves - RS. http://lad.dsc.ufcg.edu.br/ec/cr99.pdf

Shapin, S. (2010) Never Pure. Historical Studies of Sciences as if It Was Produced by People with Bodies, Situated in Time, Space, Culture, and Society, and Struggling for Credibility and Authority. The Johns Hopkins University Press, Baltimore.

Wiener, N. (1948/1985) Cybernetics or control and communication in the animal and the machine. Cambridge, MA: The MIT Press.

Wiener, N. (1950/1989) The human use of human beings: cybernetics and society. London: Free Association Books.

Woolgar, S., (1991) "Configuring the user: the case of usability trials", In: A Sociology of Monsters: Essays on Power, Technology and Domination, Ed. Law, J., Routledge, London and New York. 